\title{
High Performance Indium-Doped ZnO Gas Sensor
}

\author{
Junjie Qi, ${ }^{1}$ Hong Zhang, ${ }^{1}$ Shengnan Lu, ${ }^{1}$ Xin Li, ${ }^{1}$ Minxuan Xu, ${ }^{1}$ and Yue Zhang ${ }^{1,2}$ \\ ${ }^{1}$ School of Materials Science and Engineering, University of Science and Technology Beijing, Beijing 100083, China \\ ${ }^{2}$ Key Laboratory of New Energy Materials and Technologies, University of Science and Technology Beijing, Beijing 100083, China \\ Correspondence should be addressed to Junjie Qi; junjieqi@ustb.edu.cn and Yue Zhang; yuezhang@ustb.edu.cn
}

Received 3 November 2014; Accepted 23 December 2014

Academic Editor: Antonios Kelarakis

Copyright (C) 2015 Junjie Qi et al. This is an open access article distributed under the Creative Commons Attribution License, which permits unrestricted use, distribution, and reproduction in any medium, provided the original work is properly cited.

\begin{abstract}
Gas sensors for ethanol and acetone based on $\mathrm{ZnO}$ nanobelts with doping element indium were fabricated. Excellent sensitivity accompanied with short response time $(10 \mathrm{~s})$ and recovery time $(23 \mathrm{~s})$ to $150 \mathrm{ppm}$ ethanol is obtained. For In-doped sensors, a minimum concentration of $37.5 \mathrm{ppm}$ at $275^{\circ} \mathrm{C}$ in acetone was observed with an average sensitivity of 714.4 , which is 7 times larger than that of the pure sensors and much larger than that reported response (16) of Co-doped $\mathrm{ZnO}$ nanofibers to acetone. These results indicate that doping elements can improve gas sensitivity, which is associated with oxygen space and valence ions. In-doped $\mathrm{ZnO}$ nanobelts exhibit higher sensitivity to acetone than that to ethanol. These results indicate that doped $\mathrm{ZnO}$ nanobelts can successfully distinguish acetone and ethanol, which can be put into various practical applications.
\end{abstract}

\section{Introduction}

As we all know, volatile organic compounds (VOCs) are widely used, and vapor of some VOCs is hazardous to human health. For example, acetone in environment can cause permanent eye damage and its long-time exposure can cause kidney, liver, and nerve damage [1]. Controlling and monitoring ethanol are important in some fields as well [2], such as testing alcohol levels of drivers and monitoring chemical synthesis. Thus the detection of such hazardous and commonly used chemical is of crucial importance.

Semiconductor sensors, due to their particular advantages, such as high response, low cost, and portability, are widely used for the detection of toxic or dangerous gases and monitoring of air pollution in the environment [3]. As an n-type semiconductor, $\mathrm{ZnO}$ has been extensively used as a gas sensing material due to its high mobility of conduction electrons and good chemical and thermal stability under the operating conditions of sensors $[4,5]$. Compared with bulk and thin-film materials, the nanostructure materials exhibit a large response due to their large length-to-diameter aspect ratio and high surface-to-volume ratio, which is remarkably beneficial to the adsorption and desorption of testing gases [6].

Appropriate doping can provide electronic defects that increase the influence of oxygen partial pressure on the conductivity. Recently, the search for improving the performance of $\mathrm{ZnO}$-based gas sensors has expanded in two directions: one is doping with metal elements [7-9] or heavy metal modified [10] and the other is fabricating sensors by using one or several nanostructures as gas sensing elements $[6,11]$. Up to now, the applications of doped $\mathrm{ZnO}$ nanostructures in gas sensors have been intensively studied [12]. However, as to the majority of gas sensors based on $\mathrm{ZnO}$ films now existing, the detection concentration is still high $[13,14]$ (usually is several hundreds of ppm) and the response is relatively very low. So it is still a great challenge to reduce the limitation of detection concentration and improve the response property of the gas sensor. Moreover, there are few reports on the gas sensing of In-doped $\mathrm{ZnO}$ nanobelts. In this paper, $\mathrm{ZnO}$ nanobelts doped with indium element were synthesized and characterized. By assembling the In-doped $\mathrm{ZnO}$ nanobelts with comb-shaped gold electrodes, the high performance gas sensor was achieved. The mechanism and the influence of doping elements on the sensing characteristics were also discussed.

\section{Experimental Methods}

Pure $\mathrm{ZnO}$ nanobelts were synthesized by normal pressure thermal evaporation using zinc powders ( $99 \mathrm{wt} \%$ ) in a horizontal quartz furnace system. Before the process, substrates 
were coated with seed solution (the solution is composed of $\mathrm{Zn}\left(\mathrm{NO}_{3}\right)_{2} \cdot 6 \mathrm{H}_{2} \mathrm{O}$ and $\mathrm{CH}_{3} \mathrm{OCH}_{2} \mathrm{CH}_{2} \mathrm{OH}$; the concentration is $0.2 \mathrm{~mol} / \mathrm{L}$ ). In-doped $\mathrm{ZnO}$ nanobelts were synthesized by thermal evaporation with $\mathrm{Au}$ catalyst. The mixture of $\mathrm{Zn}$, $\mathrm{In}_{2} \mathrm{O}_{3}$, and $\mathrm{C}$ powders with the mole ratio of $5: 1: 2$ was placed in a quartz bar (with a hole in a head) inside a quartz tube as the evaporation source. A quartz substrate coated with $5 \mathrm{~nm}$ thickness of Au was then positioned on the top of the source boat. $\operatorname{Ar}(99 \mathrm{sccm})$ was used as the carrier gas, and $\mathrm{O}_{2}(1 \mathrm{sccm})$ was the reaction gas. After the reaction at a temperature of $970^{\circ} \mathrm{C}$ for $30 \mathrm{~min}$, yellow-green color samples were observed.

The morphology and structure of the synthesized product were characterized by using scanning electron microscopy (SEM: JEOL 6490) equipped with an energy dispersive X-ray spectroscopy (EDS) and X-ray diffraction (XRD, D/MAX$\mathrm{RB}$ ). Photoluminescence (PL) spectra of the synthesized products were taken at the room temperature using the $325 \mathrm{~nm}$ line of a He-Cd laser as the excitation source. An electrochemical workstation (IM6e) was used to record the resistivity of sensors, the exchange electronic potential of disturbance is $10 \mathrm{mV}$, and scan frequency ranges from 0.1 $10^{5} \mathrm{H}_{\mathrm{z}}$.

For the device assembly, ten pairs of Au interdigital electrodes $(30 \mathrm{~nm}$ thickness, with the gap of two toes being $0.4 \mathrm{~mm}$ ) were printed on an alumina ceramic substrate by a screen-printing technology using ion evaporation. Assynthesized $\mathrm{ZnO}$ nanobelts were assembled on the electrodes followed by connecting two $\mathrm{Cu}$ wires using $\mathrm{Ag}$ paste to the $\mathrm{Au}$ electrodes. The $\mathrm{ZnO}$ nanobelts sensor was connected to a computer-controlled ceramic plate heater, as shown in Figure 1(a). I-V curve of the element was measured as shown in Figure 1(b), which reveals that the contact between $\mathrm{ZnO}$ and Ag paste is ohmic contact. Compared to the resistance of the $\mathrm{ZnO}$ film, the contact resistance is so small that it can hardly influence the measurement of the gas sensing property. Therefore, the contact resistance can be omitted.

A gas distribution method was used for the test of gas sensing properties. The measurement was operated in a gas sensor test system WS-30A, which consists of a gas chamber (with heating equipment), temperature control circuit, and disturbed flow fan. The sample signals were led out and connected to IM6e electrochemical workstation. The effective volume of the chamber is $30 \mathrm{~cm} * 30 \mathrm{~cm} * 20 \mathrm{~cm}$. The volume of the gas chamber and the gas exchange speed have a great effect on the response time and recovery property. The gas diffusion was driven by the disturbed flow fan after the target gas was introduced. And then the chamber cover was moved away when the sample stabilized. The vent of the gas relies on the air diffusion driven by the disturbed flow fan. The working temperature of a sensor was adjusted through varying the heating voltage. The resistance of the chamber is preset; the heating voltage can be tuned from 1 to $10 \mathrm{v}$. The sample was assembled on the resistance gage and the resistance vale is constant, so the maximum measurement temperature is $300^{\circ} \mathrm{C}$ in our experiment. Detecting gases were injected into the test chamber and mixed with air. The heating area of sensor is smaller than the volume of test chamber, so the test chamber works at room temperature. Thus the environment of the test chamber is recognized as standard condition.

\section{Results and Discussion}

The morphology of the pure and doped $\mathrm{ZnO}$ nanobelts is shown in Figures 2(a) and 2(b), respectively. These nanobelts have a width of about 50-100 nm and a length up to dozens of micrometers. Only $\mathrm{O}$ and $\mathrm{Zn}$ elements were observed as demonstrated in EDS spectra of pure $\mathrm{ZnO}$ which are indicated in Figure 2(c). In addition to $\mathrm{O}$ and $\mathrm{Zn}$, indium element was observed as demonstrated in Figure 2(d), and the indium content was about $2.96 \%$.

XRD spectra of the as-prepared doped and undoped $\mathrm{ZnO}$ nanomaterial samples were shown in Figure 3(a), which indicate that all the samples have the wurtzite structure and no secondary phase. As compared to the standard $\mathrm{ZnO}$ powders (JCPDS No. 36-1415), a shift of the peaks to lower angle was observed in In-doped $\mathrm{ZnO}$ nanobelts, which can be attributed to lattice change caused by introduced ions [15].

Figure $3(\mathrm{~b})$ shows the room-temperature PL spectrum recorded from the as-deposited pure $\mathrm{ZnO}$ and doping $\mathrm{ZnO}$ nanobelts and part spectrum of In-doped samples ranging from 350 to $400 \mathrm{~nm}$ is shown in inset. The ultraviolet emission of pure $\mathrm{ZnO}$ is located at $390 \mathrm{~nm}$, corresponding to the near band edge (NBE) peak which is responsible for the recombination of free excitons of $\mathrm{ZnO}$ [16]. With regard to Indoped samples, a strong defects peak at $540 \mathrm{~nm}$ leads to the invisible intrinsic peak. It is likely that $\operatorname{In}^{3+}$ can combine more oxygen atoms than bivalent cations, because of the larger coordinate linkage number [15]. Therefore, there are more oxygen related defects in In-doped $\mathrm{ZnO}$, which cause a strong deep level emission.

For gas sensor, the response value (S\%) is defined as the ratio of resistance in the air $(\mathrm{Ra})$ and resistance in the tested gas ( $\mathrm{Rg}$ ) [17]. A gas distribution method was used for the test of gas sensing properties. The calculating method of concentration is as follows (taking ethanol as an example):

$$
C=\frac{V_{\text {ethanol,gas }}}{V_{s}},
$$

where $V_{\text {ethanol,gas }}$ is the volume of gaseous state ethanol, $C(\mathrm{ppm})$ is the concentration of the tested gas, and $V_{s}$ is the volume of the system's test chamber. Consider

$$
V_{\text {ethanol,gas }}=\frac{V_{\text {injection }} \times \rho \times V_{m} \times \omega}{M},
$$

where $V_{\text {injection }}$ is the volume of injection ethanol, $\rho(\mathrm{g} / \mathrm{mL})$ is the density of the liquid, $V_{m}$ is the molar volume under normal conditions, $M(\mathrm{~g} / \mathrm{mol})$ is the molar mass of ethanol, and $\omega$ is the mass fraction of the liquid. Combined with these two formulas, we can get the general formula for converting $V_{\text {injection }}$ into concentration:

$$
C=\frac{V_{\text {injection }} \times \rho \times V_{m} \times \omega}{\left(M \times V_{s}\right)} .
$$

Put the constant value that each letter stands for into formula (3):

$$
C=0.01934184 V_{\text {injection }} \mathrm{mol} / \mathrm{mL} \text {. }
$$




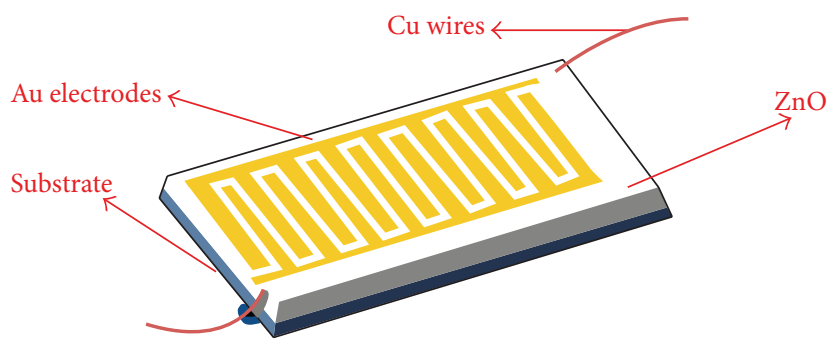

(a)

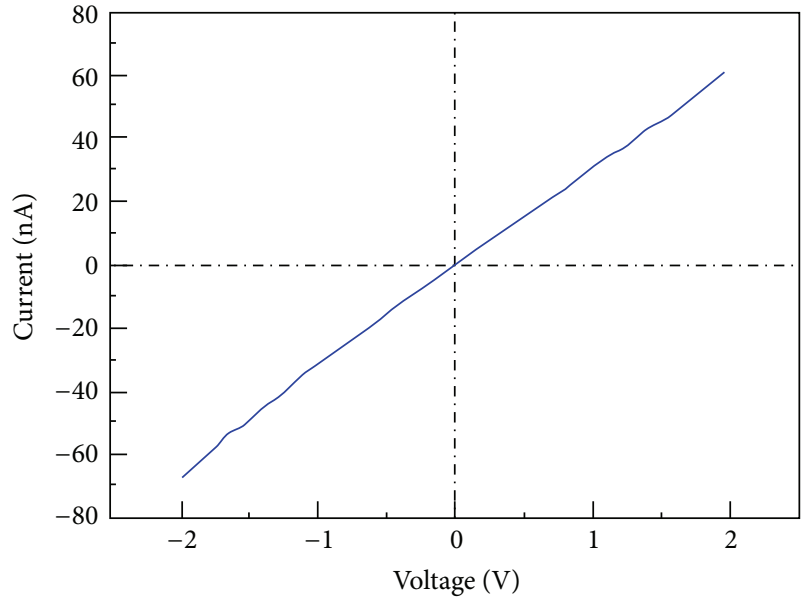

(b)

FIgURE 1: (a) Schematic of the gas sensor; (b) typical $I-V$ curve of the gas sensor.
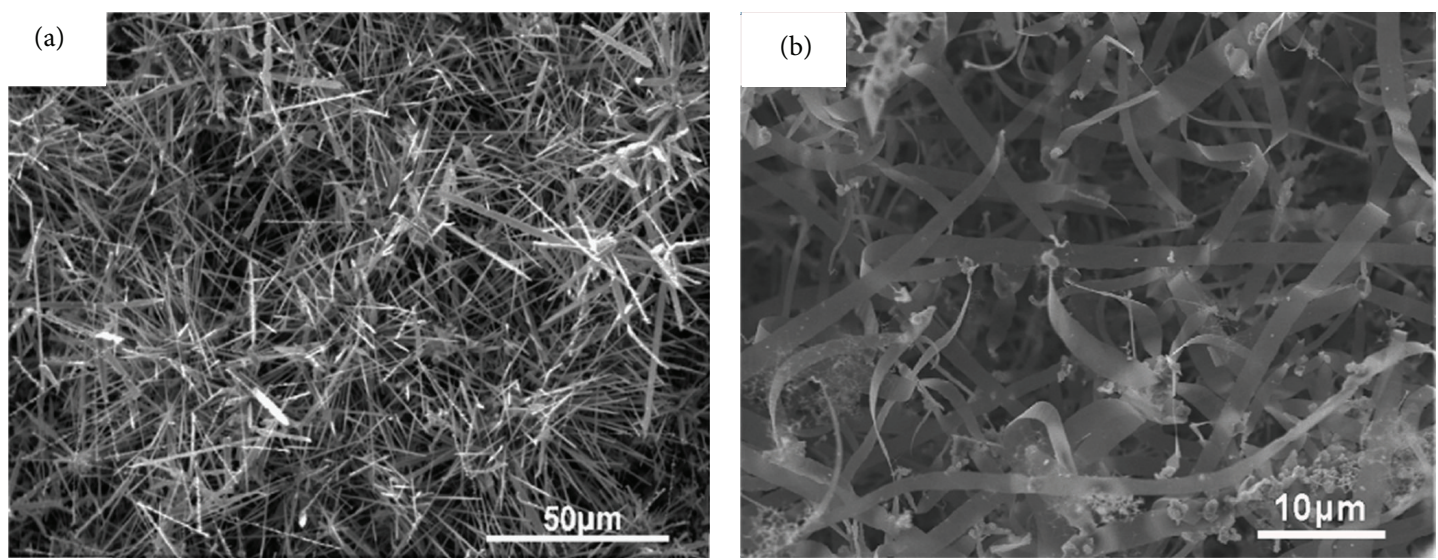

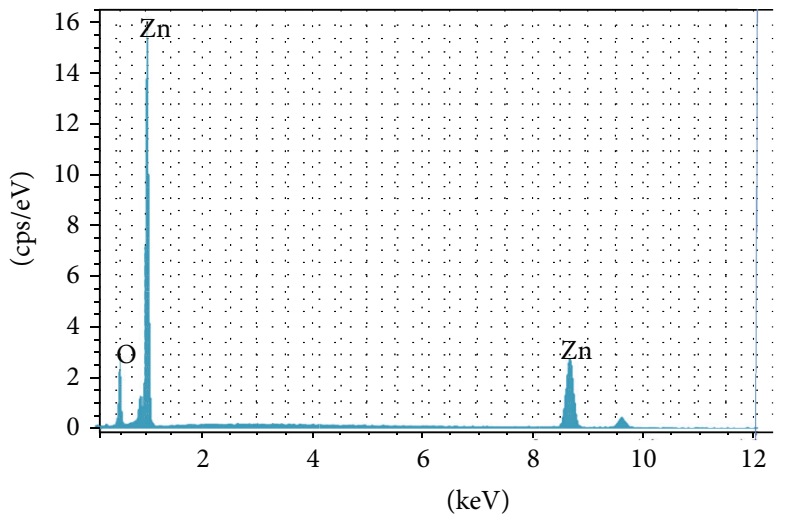

(c)

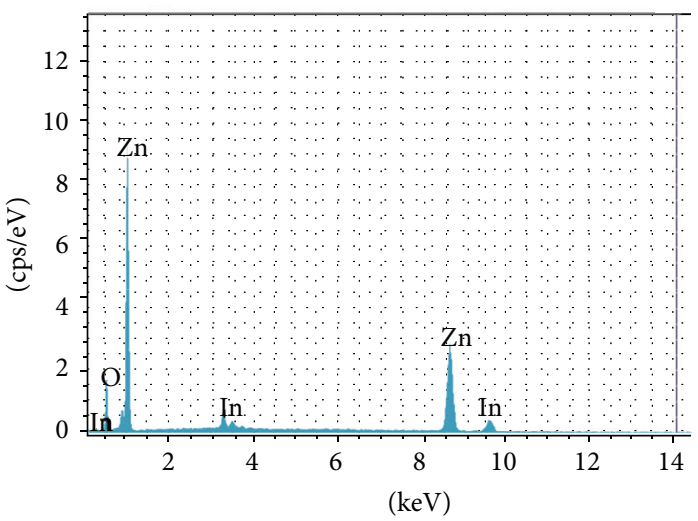

(d)

FIGURE 2: SEM images of $\mathrm{ZnO}$ nanobelts: (a) pure $\mathrm{ZnO}$; (b) In-doped $\mathrm{ZnO}$. The corresponding EDS spectrum: (c) pure $\mathrm{ZnO}$; (d) In-doped $\mathrm{ZnO}$.

In the same way, we calculated the formula which is appropriate for acetone:

$$
C=0.01511961 V_{\text {injection }} \mathrm{mol} / \mathrm{mL} \text {. }
$$

Through the two equations above, how much liquid should be injected to the test chamber to get needed concentration can be calculated. Figure 4 shows the responses of pure and doped $\mathrm{ZnO}$ samples to different concentration of ethanol and acetone at a fixed temperature $\left(275^{\circ} \mathrm{C}\right)$. In 


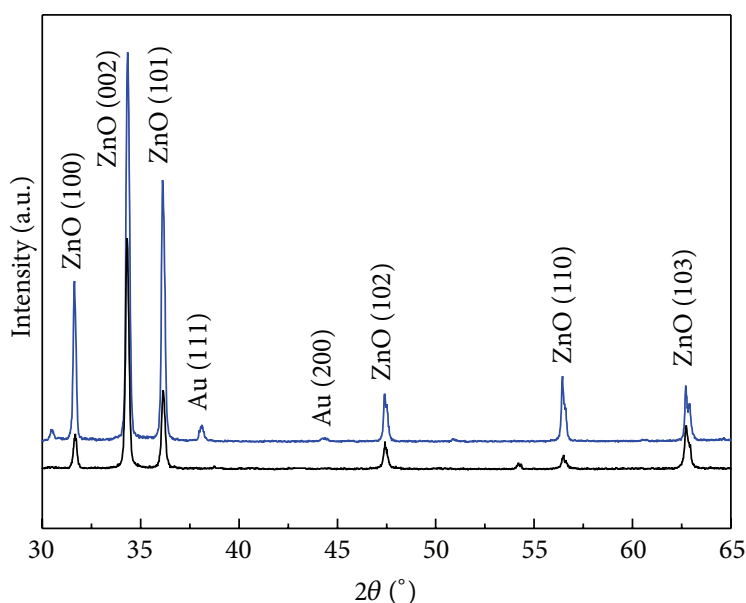

- Pure $\mathrm{ZnO}$

— In-doped $\mathrm{ZnO}$

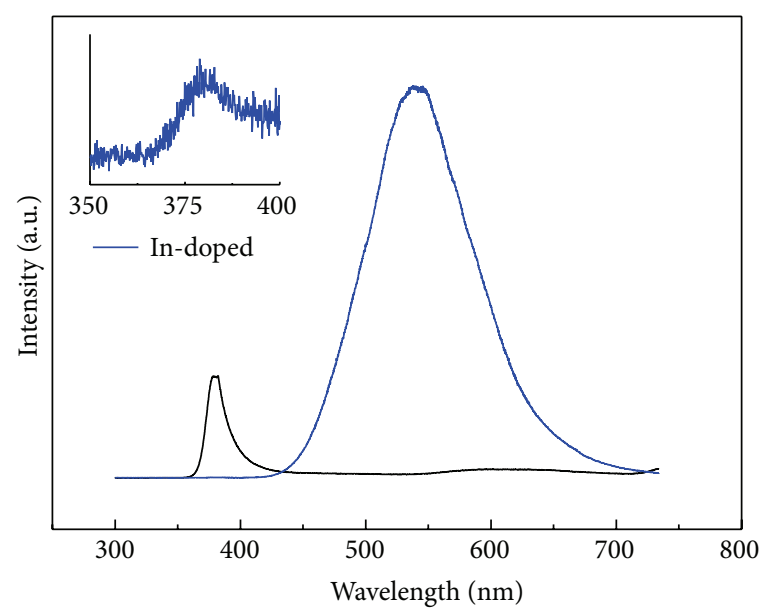

— Pure ZnO

- In-doped $\mathrm{ZnO}$

(a)

(b)

Figure 3: (a) X-ray powder diffraction patterns of pure and In-doped ZnO. (b) PL spectrum at room temperature of pure and In-doped ZnO. Wavelength from 350 to $400 \mathrm{~nm}$ of In-doped samples is shown in inset.

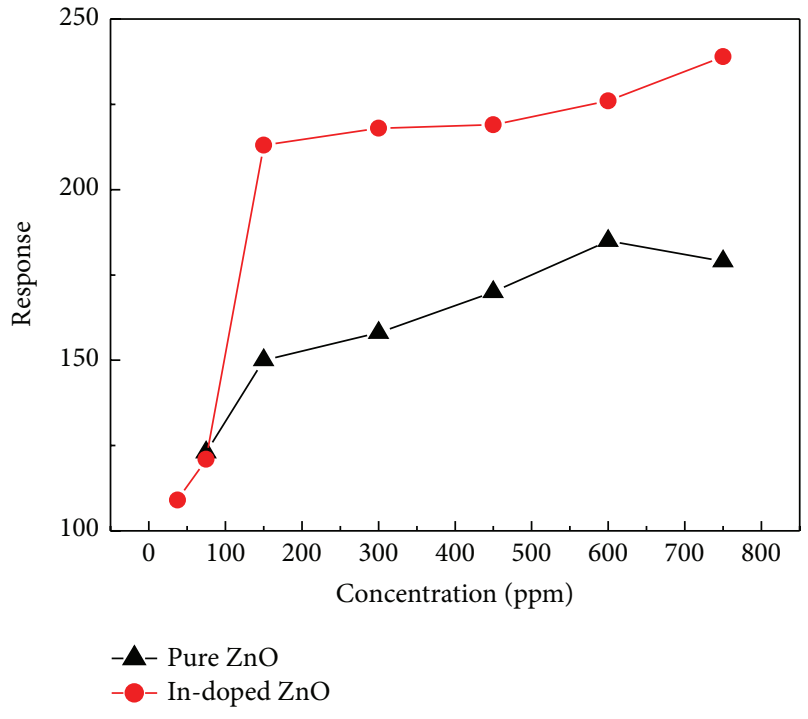

(a)

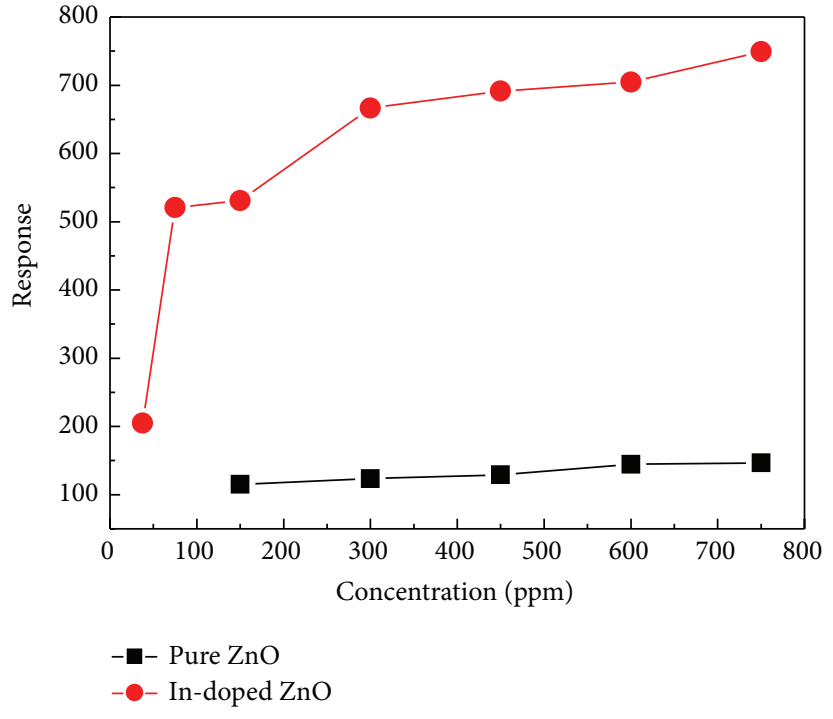

(b)

FIgURE 4: Responses of gas sensors to (a) ethanol and (b) acetone range from $37.5 \mathrm{ppm}$ to $750 \mathrm{ppm}$ at $275^{\circ} \mathrm{C}$.

the range of $37.5-750 \mathrm{ppm}$, the sensitivity of all samples is found to enhance with the increase of concentration. The average sensitivity of pure $\mathrm{ZnO}$ gas sensor at $275^{\circ} \mathrm{C}$ in ethanol ambiance is 158.4 , and the average sensitivity of In-doped $\mathrm{ZnO}$ sensor at the same condition is 220.4 , which achieved $40 \%$ increase compared with pure $\mathrm{ZnO}$ gas sensor. The detection limit of In-doped $\mathrm{ZnO}$ sensor has gone down to $37.5 \mathrm{ppm}$ compared with pure $\mathrm{ZnO}$ ones (150 ppm), as shown in Figure 4(a). Figure 4(b) displays the responses of gas sensors to acetone. The average response of In-doped sensor to acetone $\left(\mathrm{CH}_{3} \mathrm{COCH}_{3}\right)$ is 714.4 , which is 7 times larger than that of the pure $\mathrm{ZnO}$ sensor (around 100), showing higher sensitivity than the result in previous similar experiments in literatures $[18,19]$, where they reported that the response of $0.5 \mathrm{wt} \%$ Co-doped $\mathrm{ZnO}$ nanofibers to $100 \mathrm{ppm}$ acetone is only about 16 . These results indicate that In-doped $\mathrm{ZnO}$ nanobelts gas sensor can successfully distinguish acetone and ethanol, which could be put into various practical applications.

The rapid response and recovery of doped $\mathrm{ZnO}$ nanobelts gas sensor to $150 \mathrm{ppm}$ of ethanol at $275^{\circ} \mathrm{C}$ are shown in Figure 5 as compared to pure $\mathrm{ZnO}$ gas sensor. The response or recovery time is defined as the time for reaching $90 \%$ of the full response change of sensor after testing gas is introduced. It was found that the response time of the doped 


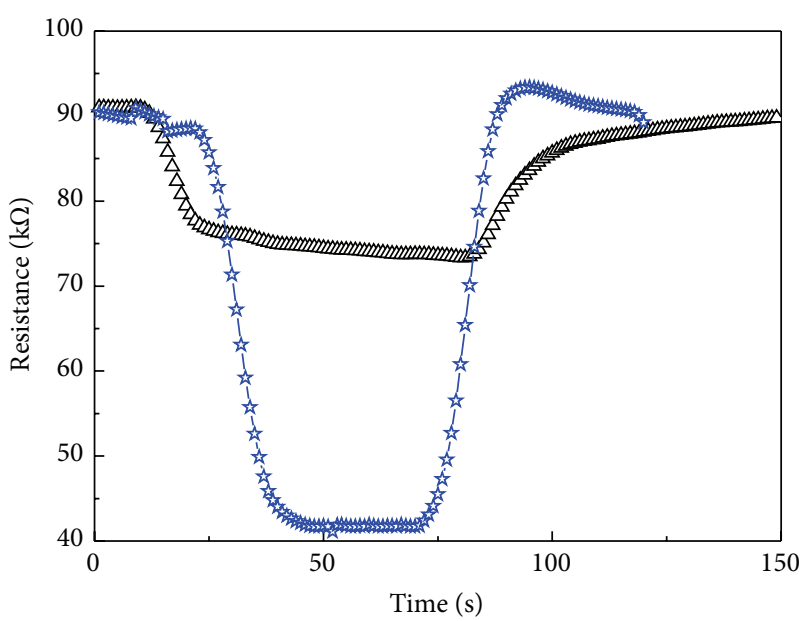

$-\triangle-$ Pure $\mathrm{ZnO}$

-

FIGURE 5: Response and recovery curve of the sensors for $150 \mathrm{ppm}$ ethanol at $275^{\circ} \mathrm{C}$.

$\mathrm{ZnO}$ sensors was less than $10 \mathrm{~s}$, whereas the recovery time was about $23 \mathrm{~s}$, both of which are much less than the pure ones. Rapid response and recovery of the sensors reveal potential value in the practical application.

Figure 6 shows the responses of pure and doped $\mathrm{ZnO}$ nanobelts gas sensor to $450 \mathrm{ppm}$ testing gas at different operating temperatures. The responses of all samples are found to increase with increasing the operating temperature. At the lower temperature scope ranging from $175 \sim 250^{\circ} \mathrm{C}$, the sensitivity grew slowly, while there is a drastic increase from $250^{\circ} \mathrm{C}$, which is possibly due to the physical adsorption of oxygen at low temperature and the chemical adsorption of oxygen at higher temperature on the surface of the sensor [20]. The sensitivity does not show saturation when the test reached to the maximum experiment temperature of $300^{\circ} \mathrm{C}$.

To measure the long-term stability of those sensors, we repeated some of the sensors many times within 2 months. During the test, no appreciable variations were detected. Thus, the obtained results showed that both sensitivity and electrical conductance were reproducible enough.

A conventional model is introduced to elaborate the gas sensing mechanism. As n-type semiconductor, $\mathrm{ZnO}$ adsorbs oxygen molecules when it is exposed to air. Absorbed oxygen can form $\mathrm{O}^{n-}\left(\mathrm{O}_{2}{ }^{-}, \mathrm{O}_{2}{ }^{2-}\right.$, and $\left.\mathrm{O}^{2-}\right)$ ions by capturing electrons from the conductance band [21]. Since gas sensors are usually operated at elevated temperature (around $573 \mathrm{~K}$ ), the $\mathrm{O}_{2}{ }^{2-}$ type is more important than other states of oxygen [22]. Since $\mathrm{ZnO}$ is a basic oxide, the target gas (ethanol) may undergo two-step decomposition reaction which comes down to a dehydrogenation process [3]:

$$
\begin{gathered}
\mathrm{O}^{n-}+n \mathrm{C}_{2} \mathrm{H}_{5} \mathrm{OH} \longrightarrow n \mathrm{CH}_{3} \mathrm{CHO}^{-}+\mathrm{H}_{2} \mathrm{O}(\mathrm{g}) \\
n \mathrm{CH}_{3} \mathrm{CHO}^{-} \longrightarrow n \mathrm{CH}_{3} \mathrm{CHO}(\text { gas })+n \mathrm{e}^{-} \\
\mathrm{CH}_{3} \mathrm{CHO}(\mathrm{ad})+5 \mathrm{O}_{2}{ }^{2-}(\mathrm{ad}) \longrightarrow 4 \mathrm{CO}_{2}+4 \mathrm{H}_{2} \mathrm{O}+10 \mathrm{e}^{-}
\end{gathered}
$$

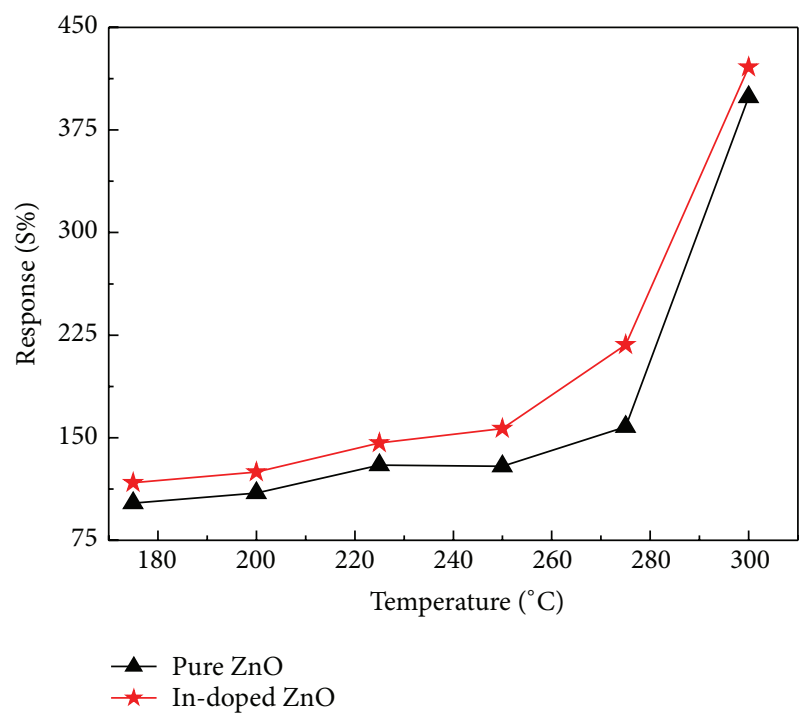

FIGURE 6: Response of the sensors exposed to ethanol gas with concentration of $450 \mathrm{ppm}$ at operating temperatures from $175^{\circ} \mathrm{C}$ to $300^{\circ} \mathrm{C}$.

The general reaction formula in acetone is given as follows:

$$
\begin{aligned}
\mathrm{H}_{3} \mathrm{COCH}_{3} \text { (ads) }+8 \mathrm{O}^{-} \text {(ads) } \longrightarrow & 3 \mathrm{CO}_{2} \text { (gas) } \\
& +3 \mathrm{H}_{2} \mathrm{O} \text { (gas) }+8 \mathrm{e}^{-}
\end{aligned}
$$

Finally, electrons return to the semiconductor, conducting the increase of electrons concentration in the conduction band. As a result, the surface resistance decreased, showing higher gas sensitivity.

The high response and short response/recovery times of In-doped $\mathrm{ZnO}$ gas sensor were attributed to many possible influencing factors. (a) The nanostructure of $\mathrm{ZnO}$ nanobelts possesses large surface-to-volume ratio, which is an important factor for high sensing performance [23]. (b) The photoluminescence (PL) spectra revealed the existence of large amount of oxygen vacancies in the doped $\mathrm{ZnO}$ nanobelts (especially in In-doped $\mathrm{ZnO}$ ), which boosts the adsorption and response of oxygen, resulting in the improved performances in the gas sensors. (c) According to the high valence ionic conduction mechanism, high metal ion $\mathrm{M}^{3+}$ which entered into $\mathrm{ZnO}$ semiconductor will form donor centre; the reaction is expressed as follows [24]:

$$
\mathrm{M}_{2} \mathrm{O}_{3}=2 \mathrm{M}_{\mathrm{Zn}}+2 \mathrm{O}_{x}+\frac{1}{2} \mathrm{O}_{2}(\mathrm{~g})+2 \mathrm{e}^{\prime}
$$

where $M_{Z n}$ represents the positive charge center which is formed by $\mathrm{M}^{3+}$ occupying the position of $\mathrm{Zn}^{2+}$ with electron losing, $\mathrm{O}_{x}$ means that oxygen atom dissociates from $\mathrm{M}_{2} \mathrm{O}_{3}$, and $\mathrm{e}^{\prime}$ is the losing electron which ionized after $\mathrm{M}^{3+}$ occupy the position of $\mathrm{Zn}^{2+}$. We could conclude that the doping of high valence ion into the semiconductor surface can produce more electrons, so the materials could absorb more gas molecules, finally leading to high performance of gas sensor. 


\section{Conclusions}

In summary, pure and In-doped $\mathrm{ZnO}$ nanobelts are synthesized by chemical vapor deposition method. Gas sensing investigation reveals that In-doping can enhance the sensing properties of $\mathrm{ZnO}$ nanobelts gas sensor efficiently in both ethanol and acetone. For the In-doped sensors, a minimum concentration of $37.5 \mathrm{ppm}$ at $275^{\circ} \mathrm{C}$ in acetone was observed with an average sensitivity of 714.4 , which is much larger than that reported response of Co-doped $\mathrm{ZnO}$ nanofibers. In particular, In-doped $\mathrm{ZnO}$ nanobelts gas sensor can successfully distinguish acetone and ethanol. The high responsivity and quick response/recovery of the gas sensors are explained by high valence ions mechanism and oxygen space effect. The results demonstrate the potential application of In-doped nanobelts for fabricating high performance gas sensors.

\section{Conflict of Interests}

The authors declare that there is no conflict of interests regarding the publication of this paper.

\section{Acknowledgments}

This work was supported by the National Major Research Program of China (2013CB932602), the Major Project of International Cooperation and Exchanges (2012DFA50990), the Program of Introducing Talents of Discipline to Universities, NSFC (51172022, 51232001), and the Program for Changjiang Scholars and Innovative Research Team in University (FRF-SD-12-032 and FRF-AS-13-001).

\section{References}

[1] T. Colborn, F. S. Vom Saal, and A. M. Soto, "Developmental effects of endocrine-disrupting chemicals in wildlife and humans," Environmental Health Perspectives, vol. 101, no. 5, pp. 378-384, 1993.

[2] L. Zhang, H. Qin, P. Song, J. Hu, and M. Jiang, "Electric properties and acetone-sensing characteristics of $\mathrm{La}_{1-x} \mathrm{~Pb}_{x} \mathrm{FeO}_{3}$ perovskite system," Materials Chemistry and Physics, vol. 98, no. 2-3, pp. 358-362, 2006.

[3] J. Xu, J. Han, Y. Zhang, Y. Sun, and B. Xie, "Studies on alcohol sensing mechanism of $\mathrm{ZnO}$ based gas sensors," Sensors and Actuators, B: Chemical, vol. 132, no. 1, pp. 334-339, 2008.

[4] M. H. Huang, S. Mao, H. Feick et al., "Room-temperature ultraviolet nanowire nanolasers," Science, vol. 292, no. 5523, pp. 1897-1899, 2001.

[5] Q. Wan, Q. H. Li, Y. J. Chen et al., "Fabrication and ethanol sensing characteristics of $\mathrm{ZnO}$ nanowire gas sensors," Applied Physics Letters, vol. 84, no. 18, pp. 3654-3656, 2004.

[6] L. Li, H. Yang, H. Zhao et al., "Hydrothermal synthesis and gas sensing properties of single-crystalline ultralong $\mathrm{ZnO}$ nanowires," Applied Physics A: Materials Science and Processing, vol. 98, no. 3, pp. 635-641, 2010.

[7] A. Yu, J. Qian, H. Pan et al., "Micro-lotus constructed by Fe-doped $\mathrm{ZnO}$ hierarchically porous nanosheets: preparation, characterization and gas sensing property," Sensors and Actuators, B: Chemical, vol. 158, no. 1, pp. 9-16, 2011.

[8] K. Zheng, L. Gu, D. Sun, X. Mo, and G. Chen, "The properties of ethanol gas sensor based on Ti doped $\mathrm{ZnO}$ nanotetrapods,"
Materials Science and Engineering B: Solid-State Materials for Advanced Technology, vol. 166, no. 1, pp. 104-107, 2010.

[9] N. Han, X. Wu, D. Zhang, G. Shen, H. Liu, and Y. Chen, "CdO activated $\mathrm{Sn}$-doped $\mathrm{ZnO}$ for highly sensitive, selective and stable formaldehyde sensor," Sensors and Actuators B: Chemical, vol. 152, no. 2, pp. 324-329, 2011.

[10] Q. Xiang, G. Meng, Y. Zhang et al., "Ag nanoparticle embedded$\mathrm{ZnO}$ nanorods synthesized via a photochemical method and its gas-sensing properties," Sensors and Actuators, B: Chemical, vol. 143, no. 2, pp. 635-640, 2010.

[11] O. Lupan, V. V. Ursaki, G. Chai et al., "Selective hydrogen gas nanosensor using individual $\mathrm{ZnO}$ nanowire with fast response at room temperature," Sensors and Actuators, B: Chemical, vol. 144 , no. 1, pp. 56-66, 2010.

[12] A. R. Raju and C. N. R. Rao, "Gas-sensing characteristics of $\mathrm{ZnO}$ and copper-impregnated $\mathrm{ZnO}$," Sensors and Actuators B: Chemical, vol. 3, no. 4, pp. 305-310, 1991.

[13] W. Xudong, D. Yong, L. Zhou, S. Jinhui, and L. W. Zhong, "Single-crystal mesoporous $\mathrm{ZnO}$ thin films composed of nanowalls," The Journal of Physical Chemistry C, vol. 113, no. 5, pp. 1791-1794, 2009.

[14] C. Gu, J. Huang, Y. Wu, M. Zhai, Y. Sun, and J. Liu, "Preparation of porous flower-like $\mathrm{ZnO}$ nanostructures and their gas-sensing property," Journal of Alloys and Compounds, vol. 509, no. 13, pp. 4499-4504, 2011.

[15] J. Zhao, X. Yan, Y. Yang, Y. Huang, and Y. Zhang, "Raman spectra and photoluminescence properties of In-doped $\mathrm{ZnO}$ nanostructures," Materials Letters, vol. 64, no. 5, pp. 569-572, 2010.

[16] T. Matsumoto, H. Kato, K. Miyamoto, M. Sano, E. A. Zhukov, and T. Yao, "Correlation between grain size and optical properties in zinc oxide thin films," Applied Physics Letters, vol. 81, no. 7, pp. 1231-1233, 2002.

[17] N. Hongsith, E. Wongrat, T. Kerdcharoen, and S. Choopun, "Sensor response formula for sensor based on $\mathrm{ZnO}$ nanostructures," Sensors and Actuators, B: Chemical, vol. 144, no. 1, pp. 67-72, 2010.

[18] S.-J. Chang, T.-J. Hsueh, I.-C. Chen et al., "Highly sensitive $\mathrm{ZnO}$ nanowire acetone vapor sensor with Au adsorption," IEEE Transactions on Nanotechnology, vol. 7, no. 6, pp. 754-759, 2008.

[19] L. Liu, S. Li, J. Zhuang et al., "Improved selective acetone sensing properties of Co-doped $\mathrm{ZnO}$ nanofibers by electrospinning," Sensors and Actuators, B: Chemical, vol. 155, no. 2, pp. 782-788, 2011.

[20] Z. Yang, Y. Huang, G. Chen, Z. Guo, S. Cheng, and S. Huang, "Ethanol gas sensor based on $\mathrm{Al}$-doped $\mathrm{ZnO}$ nanomaterial with many gas diffusing channels," Sensors and Actuators, B: Chemical, vol. 140, no. 2, pp. 549-556, 2009.

[21] N. Yamazoe, J. Fuchigami, M. Kishikawa, and T. Seiyama, "Interactions of tin oxide surface with $\mathrm{O}_{2}, \mathrm{H}_{2} \mathrm{O}$ and $\mathrm{H}_{2}$," Surface Science, vol. 86, pp. 335-344, 1979.

[22] G. S. V. Coles, G. Williams, and B. Smith, "Selectivity studies on tin oxide-based semiconductor gas sensors," Sensors and Actuators B: Chemical, vol. 3, no. 1, pp. 7-14, 1991.

[23] A. Kolmakov and M. Moskovits, "Chemical sensing and catalysis by one-dimensional metal-oxide nanostructures," Annual Review of Materials Research, vol. 34, pp. 151-180, 2004.

[24] M. T. Mohammad, A. A. Hashim, and M. H. Al-Maamory, "Highly conductive and transparent $\mathrm{ZnO}$ thin films prepared by spray pyrolysis technique," Materials Chemistry and Physics, vol. 99, no. 2-3, pp. 382-387, 2006. 

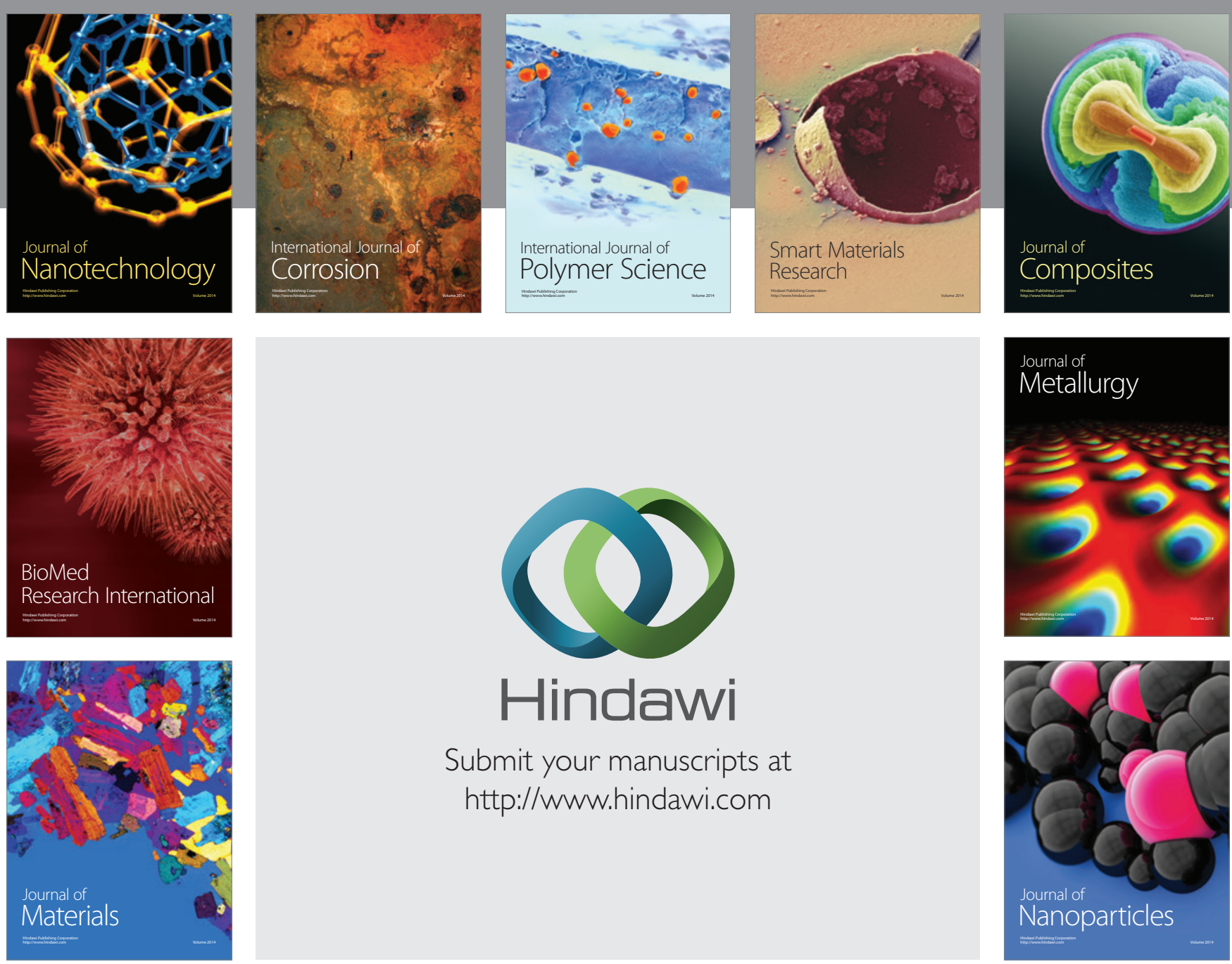

Submit your manuscripts at http://www.hindawi.com
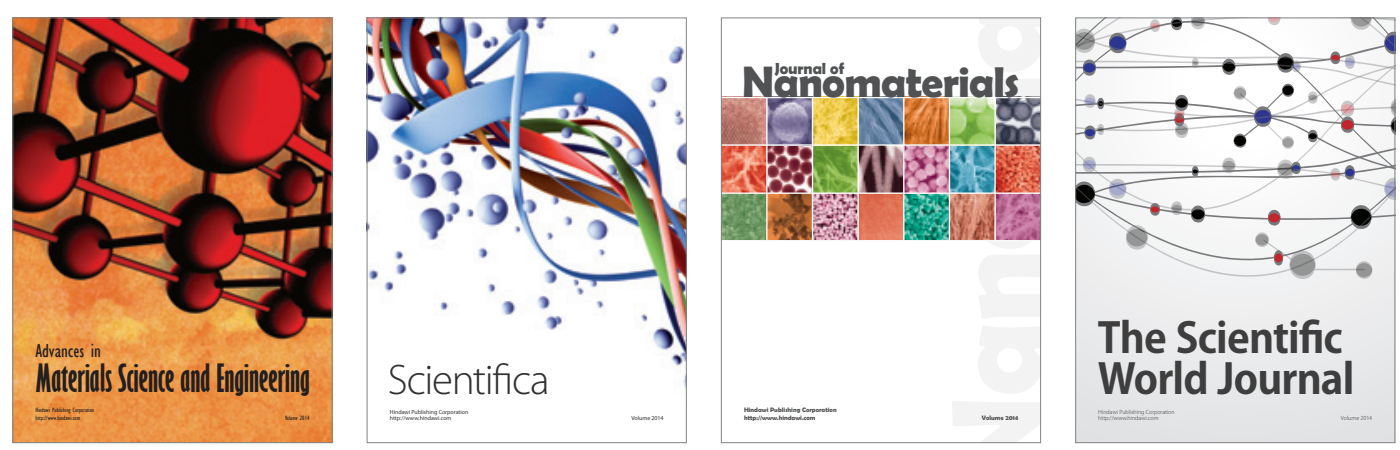

\section{The Scientific World Journal}
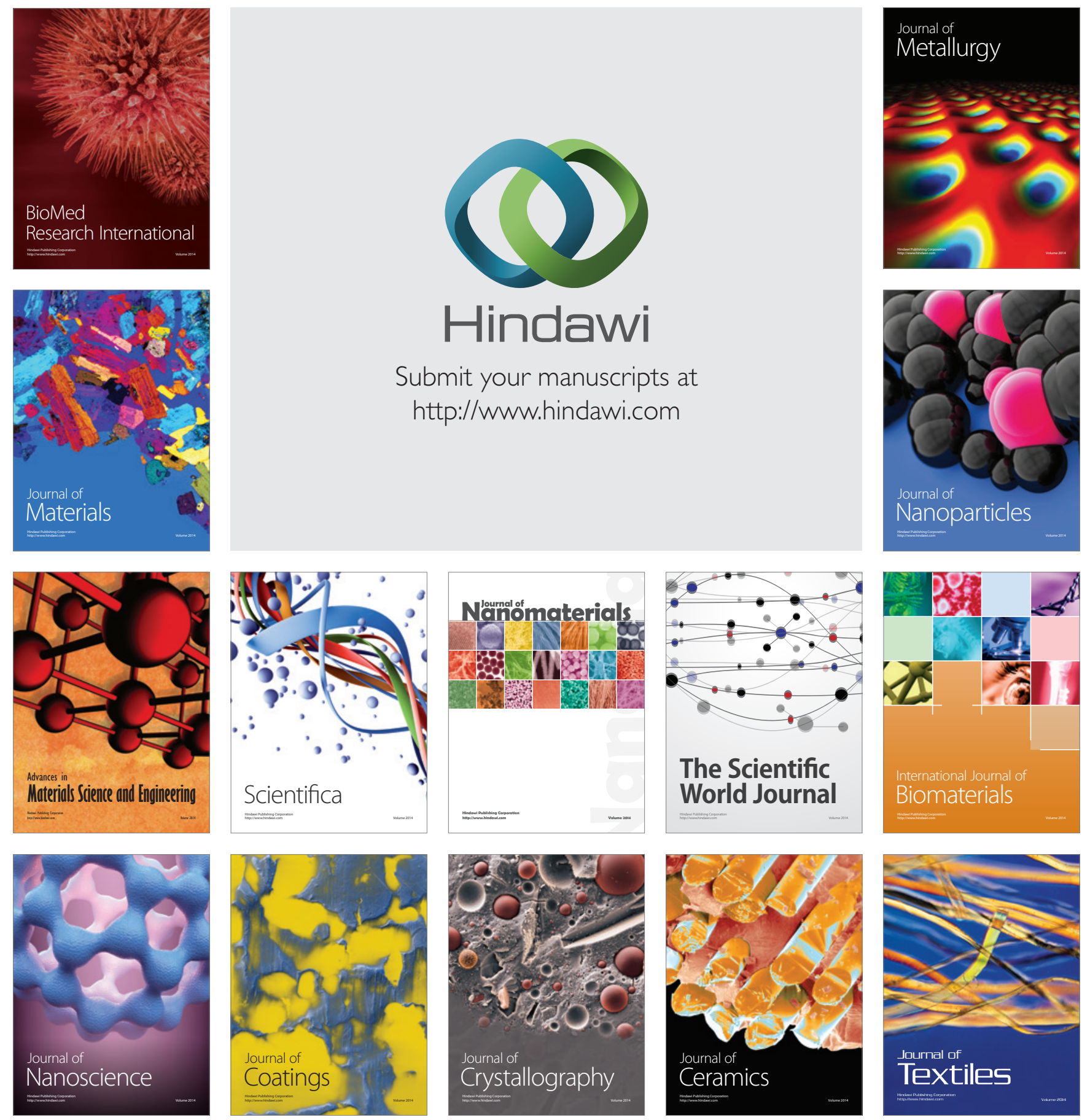